\title{
PENGARUH ABU ARANG SEBAGAI CAMPURAN BETON DITINJAU DARI KUAT TEKAN
}

Hani Purwanti., S.T., M.T; Galih Widyarini, S.T, M.T

\begin{abstract}
Abstrak
Semen portland merupakan semen hidrolis yang dihasilkan dengan cara menggiling terak semen portland terutama yang terdiri atas kalsium silikat yang bersifat hidrolis dan digiling bersama-sama dengan ditambah bahan tambahan lain (SNI 15-2049-2004). Hal ini menyebabkan adanya peningkatan harga semen setiap tahun. Dalam mengatasi permasalahan tersebut, perlu adanya suatu modifikasi pada campuran beton yang lebih ramah lingkungan. Bahan campuran yang mampu mengurangi kebutuhan semen serta mengandung kalium silikat seperti abu arang dipilih dalam bahan campuran beton modifikasi dengan meninjau kuat tekan. Tujuan penelitian ini adalah untuk mengetahui seberapa besar pengaruh komposisi abu arang sebagai pengganti semen dalam penyusunan material beton ditinjau dari kuat tekan. Adapun komposisi campuran semen yang akan digantikan dengan abu arang sebesar 0\%, 5\% dan 10\% dengan kuat tekan beton yang diharapkan memiliki mutu K-200. Adapun metode penelitian ini menggunakan metode eksperimen untuk pengambilan sampel data. Terdapat masing - masing 3 (tiga) benda uji di setiap persentase penambahan abu arang. Hasil kuat tekan beton dengan usia beton 7 hari, 22 hari dan 28 hari dalam kondisi normal tanpa campuran adalah $31 \mathrm{Mpa}, 35 \mathrm{Mpa}$, dan $38 \mathrm{Mpa}$. Kuat tekan beton yang dicampur abu arang sebanyak $5 \%$ adalah $30 \mathrm{Mpa}, 31 \mathrm{Mpa}, 36 \mathrm{Mpa}$. Pada beton campuran abu arang $10 \%$ adalah $20 \mathrm{Mpa}, 27 \mathrm{Mpa}$, dan $29 \mathrm{Mpa}$. Hasil kuat tekan dari ketiga kondisi tersebut masing masing menunjukkan adanya penurunan trend dari usia beton 7 hari, 21 hari dan 28 hari. Walaupun trend mengalami penurunan, akan tetapi nilai kuat tekan beton yang dihasilkan masih memenuhi K200.Hal tersebut menunjukkan bahwa abu arang dapat digunakan sebagai alternatif pengganti sebagian semen pada campuran beton untuk mutu beton K-200.
\end{abstract}

Kata kunci : beton modifikasi, beton campuran abu arang.

\section{PENDAHULUAN}

Beton adalah campuran antara agregat kasar dan agregat halus air dan semen yang berfungsi sebagai pengikat dan pengisi agregat kasar dan halus ditambah dengan additive (Tjokrodimulyo, 2004). Dalam perkembangan masa, harga semen setiap tahunnya mengalami peningkatan baik di Jawa maupun luar Jawa. Hal ini dikarenakan salah satunya bahan pembuat semen berasal dari alam yang merupakan bahan yang tidak dapat diperbarui, yaitu batuan yang mengandung kalsium silikat. Oleh karena itu, adanya keinginan memunculkan suatu alternatif material baru yang merupakan modifikasi dari material yang sudah ada, yaitu arang/abu arang. Arang merupakan residu hitam berisi karbon tidak murni yang dihasilkan dengan menghilangkan kandungan air dan komponen voratil dari hewan atau tumbuhan (http:wikipedia/org/wiki/arang, 2018). Dipilihnya arang sebagai alternatif pengganti semen dikarenakan arang lebih murah, lebih ringan ( berat jenis ) dan lebih mudah didapat dibandingkan semen serta arang memiliki kesamaan kandungan seperti fly ash. Akan tetapi perlu adanya pengujian kekuatan pada beton yang menggunakan arang, yaitu kuat tekan beton. Tujuan dari penelitian ini adalah untuk mengetahui hasil trend uji kuat tekan beton dari penambahan campuran arang agar memperoleh alternatif bahan penyusun beton yang digantikan abu arang dengan komposisi tertentu. Pengujian dilakukan menggunakan beton K200 dengan kondisi bahan uji normal, penambahan sebagian arang $5 \%$ dan $10 \%$. Masing-masing kondisi diujikan masing - masing sebanyak 3 buah. Benda uji diuji dalam usia beton 7 hari, 21 hari dan 28 hari. 


\section{PERANCANGAN CAMPURAN ADUKAN SEMEN}

Tahapan yang dilakukan sebelum proses pengujian beton K-200, yaitu pembuatan atau perancangan campuran adukan beton. Hasil Perancangan Campuran Adukan Beton menurut SNI 03-6861.1- 2002 dengan mutu beton K-200 untuk beton 1 M3 dapat dilihat pada Tabel 1.

Tabel 1. Rancangan Adukan Beton $1 \mathrm{~m}^{3}$

\begin{tabular}{|c|c|c|c|c|c|}
\hline No. & Uraian & Referensi atau Perhitungan & & Nilai & \\
\hline 1 & $\begin{array}{l}\text { Kuat tekan yang disyaratkan pada umur } \\
28 \text { hari }\end{array}$ & Spesifikasi & 20 & $\mathrm{MPa}$ & \\
\hline 2 & Deviasi standar (s) & Tabel 1 & - & $\mathrm{MPa}$ & \\
\hline 3 & Nilai tambah $(\mathrm{m})$ & & 7 & $\mathrm{MPa}$ & \\
\hline 4 & $\begin{array}{l}\text { Kuattekan rata-rata yang direncanakan } \\
\left(\mathrm{f}_{\mathrm{cr}}^{\prime}\right)\end{array}$ & $\mathrm{f}_{\mathrm{cr}}^{\prime}=\mathrm{f}_{\mathrm{c}}^{\prime}+\mathrm{m}$ & 27 & $\mathrm{MPa}$ & \\
\hline 5 & Jenis semen & Semen Jenis I, II, III \& IV & Tipe II & & \\
\hline 6 & Jenis agregat kasar & Alami / Batupecah & 2,7 & & \\
\hline 7 & Jenis agregat halus & Alami / buatan & 2,7 & & \\
\hline 8 & Faktor air semen & Gambar 1 & 0,58 & & \\
\hline 9 & Faktor air semen maksimum & & 0,6 & & \\
\hline 10 & Digunakan nilai FAS & & 0,57 & & \\
\hline 11 & Nilai slump & & 10 & $\mathrm{~mm}$ & \\
\hline 12 & Ukuran maksimum agregat kasar & & 10 & $\mathrm{~mm}$ & \\
\hline 13 & Kebutuhan air & & 250 & liter & \\
\hline 14 & Kebutuhan semen & & 438,6 & $\mathrm{Kg}$ & \\
\hline 15 & Kebutuhan semen minimum & & 275 & $\mathrm{Kg}$ & \\
\hline 16 & Digunakan kebutuhan semen & & 439 & $\mathrm{Kg}$ & \\
\hline 17 & Penyesuaian jumlah air atau FAS & & 0,57 & & \\
\hline 18 & Daerah gradasi agregat halus & & $100 \%$ & & \\
\hline 19 & $\begin{array}{l}\text { Persen agregat halus terhadap campuran } \\
\text { (P) }\end{array}$ & & $40-10$ & & $\%$ \\
\hline 20 & Berat jenis agregat campuran & & 2,7 & & \\
\hline 21 & Perkiraan berat beton per $\mathrm{m}^{3}$ & & 2400 & & $\mathrm{Kg} / \mathrm{m} 3$ \\
\hline 22 & $\begin{array}{l}\text { Kebutuhan agregat campuran per } \mathrm{m}^{3} \\
\text { beton }\end{array}$ & & 1711 & & $\mathrm{Kg}$ \\
\hline 23 & Kebutuhan pasir $\left(\mathrm{W}_{\mathrm{psr}}\right)$ & & 684 & & $\mathrm{Kg}$ \\
\hline 24 & Kebutuhan kerikil $\left(\mathrm{W}_{\mathrm{krk}}\right)$ & & 1027 & & $\mathrm{Kg}$ \\
\hline 25 & Kontrol berat beton & & 2400 & & $\mathrm{Kg}$ \\
\hline
\end{tabular}

Sumber : SNI 03-6861.1-2002

\section{HASIL UJI AYAK AGREGAT HALUS DAN AGREGAT KASAR}

Pengujian ayak agregat halus dilakukan untuk mengetahui golongan gradasi agregat halus. Berat contoh yang diambil sebanyak 1000 gram. Hasil dari uji ayak agregat dapat dilihat pada Tabel 2 yang menunjukkan Modulus Kehalusan $(\mathrm{MK})=4,4907$. Nilai MK tersebut mengartikan bahwa gradasi agregat halus pada Golongan II, yaitu Pasir Agak Kasar. Pada pengujian ayak agregat kasar menggunakan berat contoh 1000 gram menghasilkan nilai Modulus Kehalusan sebesar 3,241. Hasil uji ayak agregat kasar dapat dilihat pada Tabel 3. 
Tabel 2. Hasil Uji Agregat Halus

Ukuran

\begin{tabular}{|c|c|c|c|c|c|c|c|}
\hline \multicolumn{2}{|c|}{ Saringan } & \multirow{2}{*}{$\begin{array}{c}\text { Berat } \\
\text { Tertahan } \\
\text { (gram) }\end{array}$} & \multicolumn{2}{|r|}{ Komulatif } & \multicolumn{3}{|c|}{$\begin{array}{c}\text { MK Sedang } \\
\text { S.60 - 2.90 }\end{array}$} \\
\hline $\mathbf{m m}$ & inch & & $\begin{array}{c}\text { Berat } \\
\text { Tertahan }(\%)\end{array}$ & $\begin{array}{c}\text { Berat } \\
\text { Tertahan } \\
\text { Komulatif } \\
\text { (\%) }\end{array}$ & $\begin{array}{c}\text { Lolos } \\
\text { Komulatif } \\
(\%)\end{array}$ & $\begin{array}{l}\text { Batas } \\
\text { Bawah }\end{array}$ & $\begin{array}{r}\text { Batas } \\
\text { Atas }\end{array}$ \\
\hline 9,5 & $3 / 8^{\prime \prime}$ & 16,9 & 1,69 & 1,69 & 98,31 & 100 & 100 \\
\hline 4,75 & No. 4 & 48,2 & 4,82 & 6,51 & 93,49 & 90 & 100 \\
\hline 2,36 & No. 8 & 81,3 & 8,13 & 14,64 & 85,36 & 75 & 100 \\
\hline 1,18 & No. 16 & 133,3 & 13,33 & 27,97 & 72,03 & 55 & 90 \\
\hline 0,6 & No. 30 & 165,6 & 16,56 & 44,53 & 55,47 & 35 & 59 \\
\hline 0,3 & No. 50 & 214,2 & 21,42 & 65,95 & 34,05 & 8 & 30 \\
\hline 0,15 & No. 100 & 237,6 & 23,76 & 89,71 & 10,29 & 0 & 10 \\
\hline 0,075 & No. 200 & 85,6 & 8,56 & 98,27 & 1,73 & - & - \\
\hline 0,0 & PAN & 15,3 & 1,53 & 99,80 & 0,2 & - & - \\
\hline
\end{tabular}

Berat Contoh $=1000$ gram $\quad$ MK $=4,4907$

Sumber : Hasil Pengujian, 2018.

Tabel 3. Hasil Uji Ayak Agregat Kasar

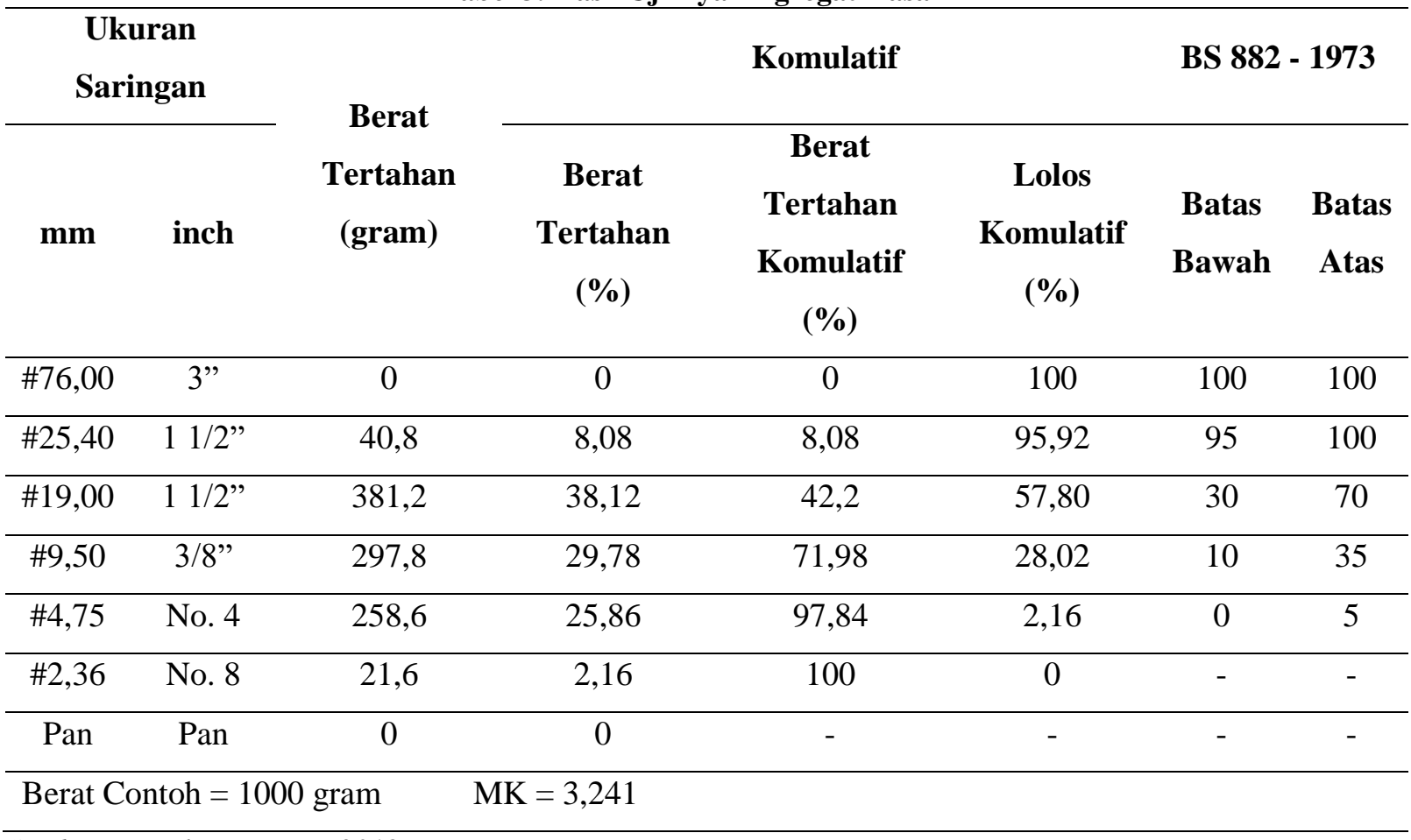

Sumber : Hasil Pengujian, 2018. 


\section{HASIL UJI TEKAN BETON}

Pengujian beton K-200 dilakukan pada 9 benda uji yang terdiri dari 3 benda uji dalam kondisi normal tanpa campuran abu arang, 3 benda uji dengan campuran abu arang sebanyak 5\% dan 3 benda uji dengan campuran abu arang 10\%. Pengujian beton dilakukan dalam 3 waktu atau umur beton yang berbeda, yaitu umur beton 7 hari, 21 hari dan 28 hari. Hasil pengujian beton dapat dilihat pada Tabel 4 dan Gambar 1.

Tabel 4. Hasil Uji Beton K-200

\begin{tabular}{|c|c|c|c|c|c|c|c|c|c|c|c|}
\hline \multirow{2}{*}{ No. } & \multirow{2}{*}{ PEKERJAAN } & \multirow{2}{*}{$\begin{array}{c}\text { TANGGAL } \\
\text { PEMBUATAN }\end{array}$} & \multirow{2}{*}{$\begin{array}{c}\text { TANGGAL } \\
\text { PENGETESAN }\end{array}$} & \multirow{2}{*}{$\begin{array}{l}\text { UMUR } \\
\text { (HARI) }\end{array}$} & \multirow{2}{*}{$\begin{array}{c}\text { BERAT } \\
\text { (KG) }\end{array}$} & \multicolumn{2}{|c|}{ UKURAN BENDA UJI } & \multirow{2}{*}{$\begin{array}{c}\text { LUAS } \\
\text { PENAMPANG } \\
\left(\mathrm{CM}^{2}\right)\end{array}$} & \multirow{2}{*}{$\begin{array}{c}\text { KUAT } \\
\text { TEKAN } \\
\text { (TON) }\end{array}$} & \multirow{2}{*}{$\begin{array}{c}\text { KOKOH } \\
\text { BETON } \\
\left(\text { KG/CM }^{2}\right)\end{array}$} & \multirow{2}{*}{$\begin{array}{c}\text { ESTIMASI } \\
28 \text { HARI } \\
\left(\text { KG/CM }{ }^{2}\right)\end{array}$} \\
\hline & & & & & & $\begin{array}{c}\text { DIAMETER } \\
\text { (CM) }\end{array}$ & $\begin{array}{l}\text { TINGGI } \\
\text { (CM) }\end{array}$ & & & & \\
\hline 1 & NORMAL & 16-Apr-18 & 23-Apr-18 & 7 & 12,195 & 15,00 & 30,00 & 176,625 & 31 & 211,46 & 302,09 \\
\hline 2 & $5 \%$ & 16-Apr-18 & 23-Apr-18 & 7 & 11,750 & 15,00 & 30,00 & 176,625 & 30 & 204,64 & 292,34 \\
\hline 3 & $10 \%$ & 16-Apr-18 & 23-Apr-18 & 7 & 11,650 & 15,00 & 30,00 & 176,625 & 20 & 136,43 & 194,90 \\
\hline 4 & NORMAL & 16-Apr-18 & 8-May-18 & 22 & 11,887 & 15,00 & 30,00 & 176,625 & 35 & 238,75 & 247,41 \\
\hline 5 & $5 \%$ & 16-Apr-18 & 9-May-18 & 23 & 11,733 & 15,00 & 30,00 & 176,625 & 32 & 218,28 & 224,80 \\
\hline 6 & $10 \%$ & 16-Apr-18 & 9-May-18 & 23 & 11,695 & 15,00 & 30,00 & 176,625 & 27 & 184,18 & 189,68 \\
\hline 7 & NORMAL & 16-Apr-18 & 14-May-18 & 28 & 12,110 & 15,00 & 30,00 & 176,625 & 38 & 259,21 & 259,21 \\
\hline 8 & $5 \%$ & 16-Apr-18 & 14-May-18 & 28 & 11,836 & 15,00 & 30,00 & 176,625 & 36 & 245,57 & 245,57 \\
\hline 9 & $10 \%$ & 16-Apr-18 & 14-May-18 & 28 & 11,720 & 15,00 & 30,00 & 176,625 & 29 & 197,82 & 197,82 \\
\hline
\end{tabular}

Sumber : Hasil Pengujian, 2018.

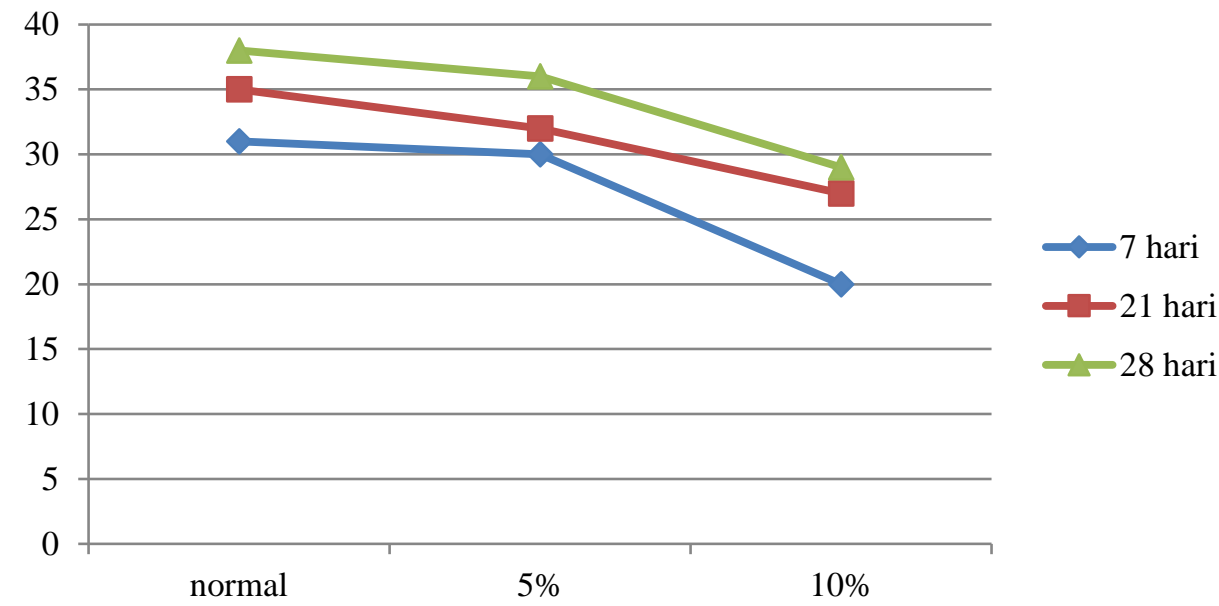

Sumber : Hasil Pengujian, 2018

Gambar 1. Trend Hasil Kuat Tekan Beton K-200 dengan Campuran Abu Arang

Tabel 2 menunjukan hasil kuat tekan beton dengan usia beton 7 hari, 21 hari dan 28 hari dalam kondisi normal tanpa campuran adalah $31 \mathrm{Mpa}, 35 \mathrm{Mpa}$, dan $38 \mathrm{Mpa}$. Pada beton yang dicampur abu arang sebanyak $5 \%$ adalah $30 \mathrm{Mpa}, 31 \mathrm{Mpa}, 36 \mathrm{Mpa}$. Pada beton campuran abu arang 10\% adalah 20 Mpa, $27 \mathrm{Mpa}$, dan 29 Mpa. Hasil kuat tekan dari ketiga kondisi tersebut masing - masing menunjukkan adanya penurunan trend dari usia beton 7 hari, 21 hari dan 28 hari. Walaupun trend mengalami penurunan, akan tetapi nilai kuat tekan beton yang dihasilkan masih memenuhi K-200. Hal tersebut menunjukkan bahwa abu arang dapat digunakan sebagai alternatif pengganti sebagian semen pada campuran beton untuk mutu beton K-200. 


\section{KESIMPULAN}

Arang yang memiliki unsur kandungan silika, dapat digunakan sebagai alternatif campuran pengganti sebagian semen pada beton K-200. Walaupun nilai trend kuat tekan tidak mengalami kenaikan, akan tetapi besar kuat tekan yang dihasilkan masih memenuhi K-200.

\section{DAFTAR PUSTAKA}

SNI 15-2049-2004, Semen Portland. SNI 03-6861.1-2002, Bahan Bangunan Bukan Logam.

Tojkrodimuljo, Kardiyono. 2004. Teknologi Beton. Nafiri. Yogyakarta.

http : wikipedia/org/wiki/arang. 2018 